\title{
Effects Study of Electrical Parameters on the Machined Surface Properties of TC4 Titanium Alloy
}

\author{
Zhaoyuan Zhang ${ }^{1, a^{*}}$ and Hai Peng ${ }^{2, b}$ \\ ${ }^{1.2}$ School of Mechanical Engineering, Xi'an Shiyou University, Xi'an, Shaanxi (710065), China \\ a1044131624@qq.com, ${ }^{b} h p e n g 1104 @$ sina.com
}

Keyword: Titanium alloy; Electrical machining parameters; Electric machining

\begin{abstract}
In this paper, the characteristics of TC4 titanium alloy material which is difficult to be machined by traditional mechanical processing were analyzed. Therefore, the short electric arc machining system was used to test the titanium alloy, and the influence of different machining parameters on the material removal quantity and surface roughness of the machined material were compared. Electric machining has the characteristics of high processing efficiency and without cutting force. Accordingly, the microstructure and mechanical properties of the surface layer of the machined titanium alloy were tested and analyzed. Finally, we can draw a conclusion that the thickness and hardness of the heat affected layer have little influence on the properties of the titanium alloy, the metallographic structure of the machined surface layer is still easy to be second processing and no high-temperature sintering phenomenon. This research provides a necessary theoretical basis and technological methods for the electric machining technology in machining applications of special difficult to machine materials.
\end{abstract}

\section{Introduction}

With the progress of manufacturing industry, traditional materials have been unable to meet the needs of special production, but special materials with high strength, high hardness, high temperature resistance and corrosion resistance are become widely popular. Among them, titanium alloys have been widely used in aerospace, military and petroleum logging because of its high specific strength, corrosion resistance, high temperature resistance and light weight. However, the advantages of titanium alloy will be hard to machine with traditional machining methods. Given the high thermal strength, poor thermal conductivity of the titanium alloy, the material's surface will form a hardened layer during the machining, which will cause the large cutting force and high cutting temperature[1]. And the elastic modulus of titanium alloy is low, likely to produce elastic deformation, and caused a large amount of springback in the machining surface and adhesive wear of the tool flank. Short electric machining is a technology that uses short arc system to generate arc discharge in processing area to produce high temperature to melt and remove excess part of workpiece surface, this technology has advantages of no cutting force, high machining efficiency and easy control[2]. Therefore, effects study of this technique on the machined surface properties of titanium alloy material is a new exploration of approach to the processing of difficult-to-machine materials.

\section{Test and analysis of the electric arc machining TC4 titanium alloy}

Short electric arc machining test system. Short electric arc machining test system is a new type of non-contact special processing technology, which uses the electric arc produced by short electric arc cutting power between the workpiece and tool to dissolve excess material of workpiece surface, and the dissolved excess material can be removed from the workpiece substrate by the gas-liquid mixing device. At present the processing method is mainly applied to the high strength, high hardness materials roughing and semi-finishing of cylindrical[3]. This technology can process all conductive materials, and materials workability is not affected by the material mechanical properties. When machining the workpiece and cutting tool without cutting force, the workpiece does not produce plastic deformation, and the processing precision is easy to be controlled, while short electric arc 
machining has higher material removal rate, this technology can effectively solve the technical problems of excessive cutting temperature and severe cutting tool wear in the traditional mechanical processing [4]. The processing experimental system diagram as shown in Fig 1.

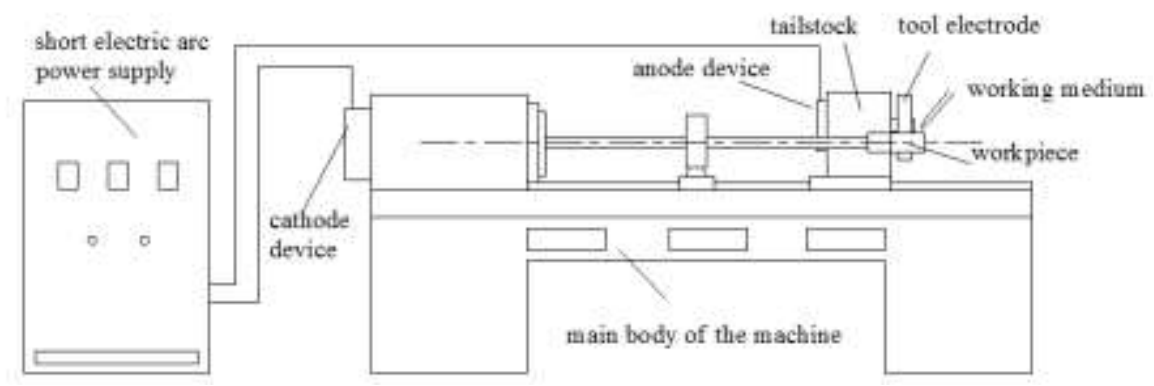

Figure 1. Schematic diagram of short electric arc machining system

The short electric arc machining system is composed of the main body of the machine, short electric arc power supply, anode and cathode device, tool electrode, machined workpiece and working medium. The power supply is DHX33A3000/28FS short arc electric cutting power supply, whose working current can reach $2000 \mathrm{~A}$ and the voltage range is $0 \sim 30 \mathrm{~V}$. The tool electrode is made of carbon steel as a cutter head, and its used as a discharge electrode together with the processed workpiece, because of the polarity effect of electrode head in EDM, the loss of anode electrode is greater than cathode electrode. Therefore, the tool electrode is fixed on the cathode device and connected to negative pole of short electric arc power supply, and the processed workpiece is fixed on the anode device and connected to positive pole of short electric arc power supply. Meanwhile, the tool electrode and the processed workpiece should be kept a certain gap and both must be taken insulation measures, the workpiece is rotated while the tool electrode makes a relative rotation during machining. In the meantime, the emulsion medium with a certain pressure effects between tool electrode and processed workpiece. When the tool electrode gradually closes to the processed workpiece and the distance between them allows discharge, it will produce a strong arc discharge between them so that local material on the surface of the processed workpiece to be melted, and under the action of the working medium, the melted material is stripped and cooled down until the workpiece processing size is reached. The short electric arc processing method is similar to the high speed grinding [5]. The principle of short electric arc machining is shown in Fig 2.

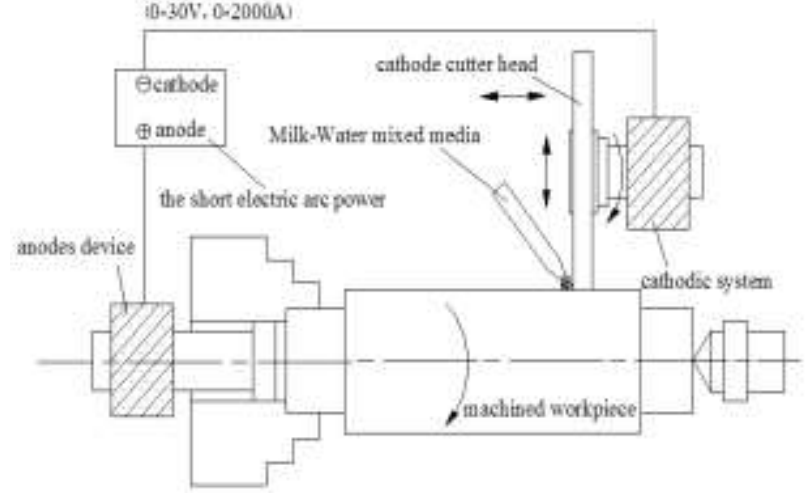

Figure 2. The principle of short electric arc machining



Figure 3. The test machining process

In the process of electric machining, the electric field is formed between the workpiece and tool when the supply voltage is applied, electric field intensity is gradually increasing with the decrease of the gap between the two electrodes. When the gap between the electrodes reaches a critical distance of the arc discharge, the surface of the cathode will release electron, while impacts on the anode at high speed under the action of electric field force, then a conductivity discharge channel is formed. As a large number of electrons move within the channel, electrical energy is converted into heat energy, making high temperature on the surface of the electrode, but polarity effect makes the anode surface produce more high temperature than cathode. The workpiece surface material is 
melted, gasificated and splashed away in the high temperature conditions, most processed particles are washed away from the working area by the liquid medium, but others will be adsorbed on the electrode surface to compensates the electrode, thus the process is finished [6].

Effects of electrical machining parameter on the electrical processability to TC4 titanium alloy. Processing materials of this experiment is TC4 titanium alloy. Outer diameter of the workpiece is $\Phi 60 \mathrm{~mm} * 500 \mathrm{~mm}$. The electrode is carbon steel cutterhead, which is $\Phi 675 \mathrm{~mm}$ and $10 \mathrm{~mm}$ thick. Working medium is the emulsion with a certain pressure. The experimental scheme is that compare and analyze the influence rule on the surface roughness, material removal amount, and the material removal rate with different machining parameters of electrical or non-electrical. The test machining process as shown in Fig 3.

Discharge gap as one of the main processing parameters has a great influence on electric machining performance in electrical arc processing. Due to the smaller the gap, the greater the electric field strength between the two electrodes, and best machining effect can be determined by changing the discharge gap. Under the test conditions of the workpiece speed $60 \mathrm{r} / \mathrm{min}$ and the supply voltage $15 \mathrm{~V}$, when the discharge gap reaches at $1.5 \mathrm{~mm}$, the discharge arc and small discharge spark are generated between two electrodes, which means $1.5 \mathrm{~mm}$ is the maximum discharge gap, followed arc machining experiment was carried out by changing the discharge gap. The processed surface characteristics are shown in Fig 3, three sections shown from left to right are the discharge gaps on the machined surface at $0.6 \mathrm{~mm}, 0.4 \mathrm{~mm}$ and $0.2 \mathrm{~mm}$ in turn. The results were obtained through the measurement and calculation, as shown in Table 1.

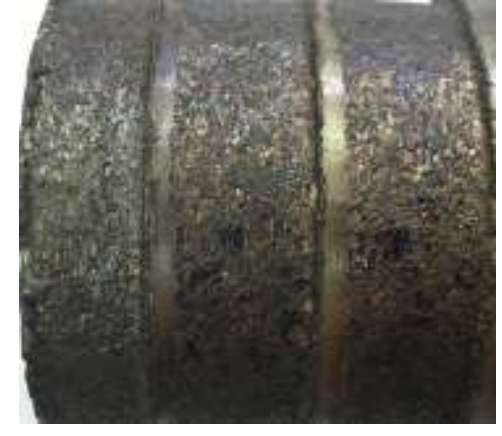

Figure 4. The surface characteristics of TC4 under different discharge gaps



Figure 5. The relationship between discharge gap and removal rate

Table 1 Experimental results

\begin{tabular}{|c|c|c|c|c|c|c|}
\hline material & $\begin{array}{c}\text { discharge } \\
\text { gap(mm) }\end{array}$ & $\begin{array}{c}\text { discharge } \\
\text { current(A) }\end{array}$ & $\begin{array}{c}\text { processing } \\
\text { time(s) }\end{array}$ & $\begin{array}{c}\text { surface } \\
\text { roughness }(\mu \\
\mathrm{m})\end{array}$ & $\begin{array}{c}\text { removal } \\
\text { amount }(\mathrm{g})\end{array}$ & $\begin{array}{c}\text { removal } \\
\text { rate(g/s) }\end{array}$ \\
\hline \multirow{2}{*}{$\begin{array}{c}\text { TC4 } \\
\text { Titaniu } \\
\text { m alloy }\end{array}$} & 0.6 & 150 & 25 & 52.95 & 7.28 & 0.29 \\
\cline { 2 - 7 } & 0.4 & 400 & 19 & 61.49 & 10.09 & 0.57 \\
\hline
\end{tabular}

From Fig 4 and Table 1, it can be observed that the smaller the discharge gap, the higher the surface roughness of the workpiece, and the worse the surface quality. Accordingly, the larger discharge gap should be selected when the surface quality requirement of workpiece is high. From Table 1 and Fig 5, the discharge gap is increased, the removal quantity of the workpiece is decreased, the processing time of workpiece is increased, and the removal rate is reduced. This main reason is the smaller discharge gap, the stronger electric field intensity of the discharge channel. It results that energy is aggregated, the heat on the workpiece surface is risen and removed metal is increased. Therefore, the machining efficiency is improved, but the workpiece surface pit is obvious, and the surface quality becomes worse.

Discharge voltage as a electric processing parameters which has a greater impact on the arc machining effect, and the proper voltage parameters is a key of arc machining. The test conditions 
of the workpiece use speed $60 \mathrm{r} / \mathrm{min}$, discharge gap $0.4 \mathrm{~mm}$ and followed by changing the voltage for electric machining test. The processed surface features as shown in Fig 5. Three discharge voltages on processing surface are $10 \mathrm{~V}, 15 \mathrm{~V}$ and $20 \mathrm{~V}$ from left to right in the section. The calculated results of the measurements are shown in Table 2.

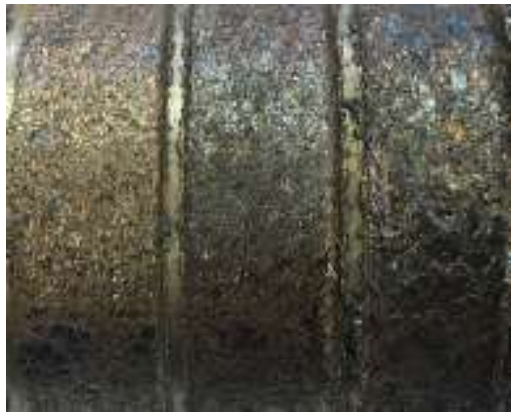

Figure 6. The surface characteristics of TC4 under different voltage

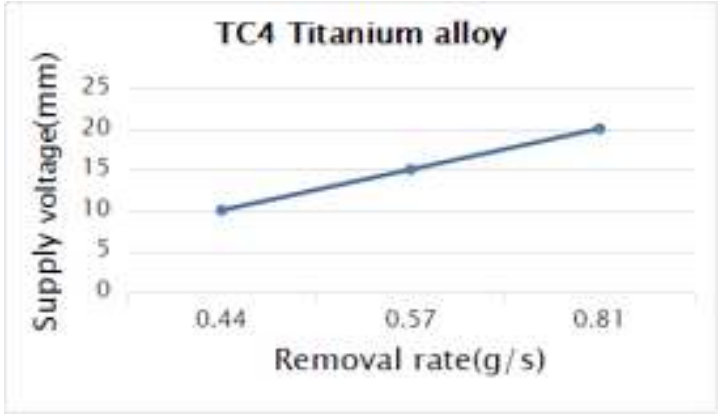

Figure 7. The relationship between discharge voltage and removal rate

Table 2 Experimental results

\begin{tabular}{|c|c|c|c|c|c|c|}
\hline material & $\begin{array}{c}\text { supply } \\
\text { voltage(mm } \\
)\end{array}$ & $\begin{array}{c}\text { discharge } \\
\text { current(A) }\end{array}$ & $\begin{array}{c}\text { processing } \\
\text { time(s) }\end{array}$ & $\begin{array}{c}\text { surface } \\
\text { roughness }(\mu \\
\mathrm{m})\end{array}$ & $\begin{array}{c}\text { removal } \\
\text { amount }(\mathrm{g} \\
)\end{array}$ & $\begin{array}{c}\text { removal } \\
\text { rate(g/s) }\end{array}$ \\
\hline \multirow{2}{*}{$\begin{array}{c}\text { TC4 } \\
\text { Titanium } \\
\text { alloy }\end{array}$} & 10 & 310 & 19 & 53.06 & 8.41 & 0.44 \\
\cline { 2 - 7 } & 15 & 450 & 20 & 62.04 & 10.95 & 0.57 \\
\hline
\end{tabular}

It can be seen from Fig 6 that the increased power supply voltage can cause workpiece surface roughness increases and surface quality decreases. So the lower discharge voltage can get better surface quality. It can be concluded from the Table 2 and Fig 7 that when the supply voltage increases, the processing discharge current was increases and metal removal quantity was increases in unit time, and increasing the amount of removal rate. Analysis of the main reason is that the power supply voltage increases, discharge channel current also increases, channel of electric field intensity and energy increases, all of which cause the amount of heat absorbed on the workpiece surface increased, and the molten metal material and removal rate increased in unit time. At the same time, it will cause that the metal droplets become bigger, the surface pit of the workpiece is more obvious, increases of surface roughness, and the surface quality becomes worse.

Workpiece speed also will affect the result of the arc machining even though it is not electric machining parameters. Setting the power voltage to $15 \mathrm{~V}$, the discharge gap to $0.4 \mathrm{~mm}$, and followed by changing the workpiece speed for electric machining test. Because of high speed will cause vibration, the speed of the workpiece should be kept at a certain speed range to ensure the machining process stability. The discharge current is larger at the beginning of processing, and the experiment is stopped when the electric current decline to 50A, the Fig 7 below shown the processed structure of the surface part. The three sections processed surfaces respectively are belong to three different workpiece speeds with $60 \mathrm{r} / \mathrm{min}, 118 \mathrm{r} / \mathrm{min}$, and $190 \mathrm{r} / \mathrm{min}$ in turn. The results of the measurement and calculation are showed in the Table 3 below. 


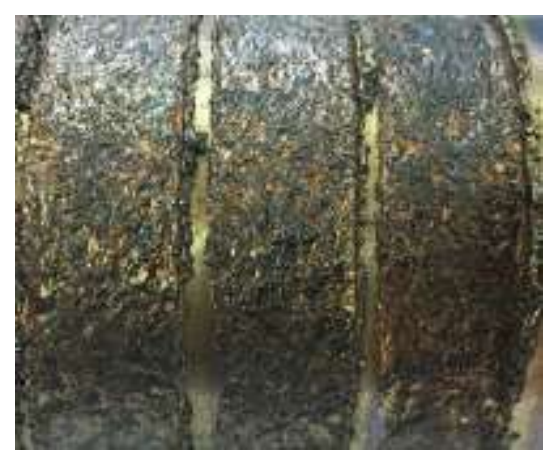

Figure 8. The surface characteristics of TC4 under different speed

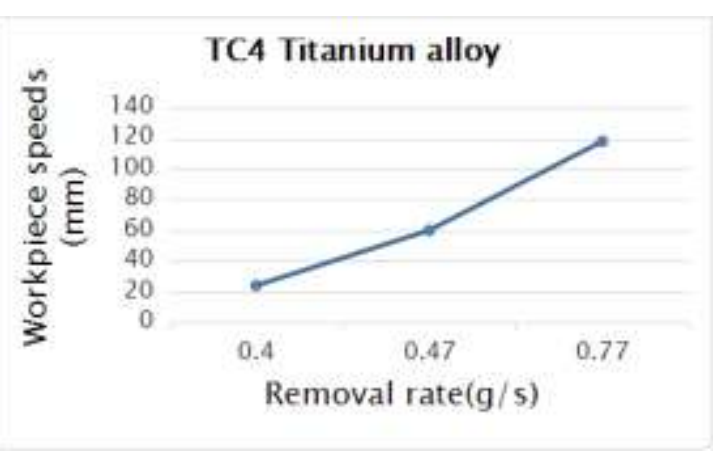

Figure 9. The relationship between spindle speed and removal rate

Table 3 Experimental results

\begin{tabular}{|c|c|c|c|c|c|c|}
\hline material & $\begin{array}{c}\text { workpiece } \\
\text { speeds }(\mathrm{mm})\end{array}$ & $\begin{array}{l}\text { discharge } \\
\text { current(A) }\end{array}$ & $\begin{array}{c}\text { processing } \\
\text { time }(S)\end{array}$ & $\begin{array}{c}\text { surface } \\
\operatorname{roughness}(\mu \\
\mathrm{m})\end{array}$ & $\begin{array}{c}\text { removal } \\
\text { amount }(\mathrm{g})\end{array}$ & $\begin{array}{l}\text { removal } \\
\operatorname{rate}(\mathrm{g} / \mathrm{s})\end{array}$ \\
\hline \multirow{3}{*}{$\begin{array}{c}\text { TC4 } \\
\text { Titaniu } \\
\text { m alloy }\end{array}$} & 60 & 280 & 26 & 55.89 & 10.28 & 0.40 \\
\hline & 118 & 430 & 22 & 57.53 & 10.50 & 0.47 \\
\hline & 190 & 510 & 15 & 59.65 & 11.64 & 0.77 \\
\hline
\end{tabular}

From Fig 8 and Table 3 we can learn that the surface quality change of the workpiece is not obvious under different spindle speed. From the Table 3 and Fig 9, we can know that the spindle speed increased, the electric current is increased, the processing time is shorten, the removal amount is increased, and the removal efficiency is improved. The prime reason is that the spindle speed is increased, at the same time, the discharge process between workpiece and tool electrode will increase and then the removed amount of materials will be increased.

Detection and analysis the surface layer performance machined by electric machining

Electric machining belongs to the range of rough machining. The surface layer metal structure of titanium alloy TC4 will be sintered, which is caused by the high temperature during the electric processing. Accordingly, the material's mechanical properties will be changed too. Therefore, through examination and analysis the metallographic structure of material, we can understand the change of the metallurgical structure and the influence level of the electrical processing on material properties. Axio Observer Digital Material Microscope and HXD-1000TMC Microhardness Tester are used to observe and measure the organization structure and the surface hardness of the workpiece. Fig 10and 11 are the surface organization change of TC4 titanium alloy after and before the experiment.

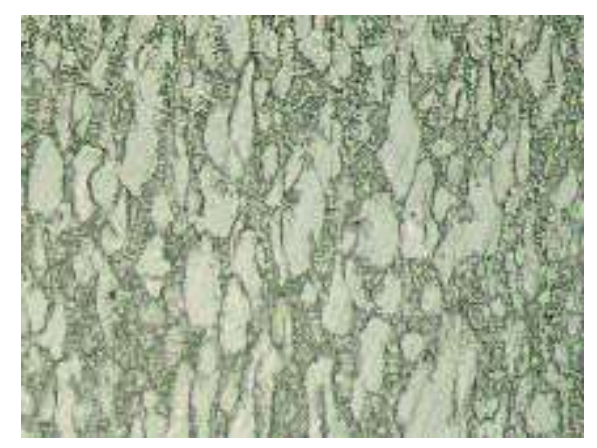

Figure 10 Matrix structure before processing(500x)

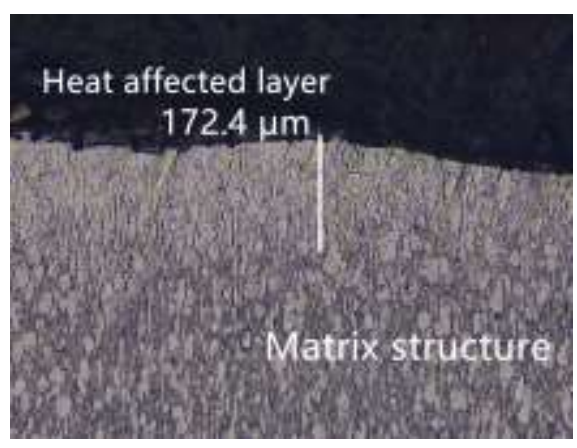

Figure 11. Matrix structure after processing $(400 \times)$

Four points were selected from TC4 titanium alloy workpiece for testing the changes of surface hardness before and after the experiment. The below Table 4 shows the results. 
Table 4 Hardness variation of TC4 titanium alloy

\begin{tabular}{|c|c|c|}
\hline \multirow{4}{*}{$\begin{array}{c}\text { TC4 titanium } \\
\text { alloy }\end{array}$} & short electric arc before machining & short electric arc after machining \\
\cline { 2 - 3 } & $336.9 \mathrm{HB}$ & $437.4 \mathrm{HB}$ \\
\cline { 2 - 3 } & $328.4 \mathrm{HB}$ & $414.6 \mathrm{HB}$ \\
\hline & $332.2 \mathrm{HB}$ & $432.3 \mathrm{HB}$ \\
\hline Arithmetic mean & $329.9 \mathrm{HB}$ & $402.5 \mathrm{HB}$ \\
\hline
\end{tabular}

From Fig 9, it can be known that the structure of TC4 is equiaxed, it is mixed $\alpha$ phase and $\beta$ phase. From the Fig 10 we can know that the thickness of the heat-affecting layer is small, about $172.4 \mu \mathrm{m}$. The picture shows that the surface part is recast layer structure, which is concretion of cooled melting metal. The middle is heat affected zone and the metallographic structure shows grain refinement[7]. Due to the surface part has been influenced by the high temperature during the processing, and the heat was concentrated in this region, the $\beta$ phase will turn into acicular martenstic structure when it was fast cooled by cooling water, the grains were deformed to irregular structure which is longer and narrower than matrix structure. This process is similar to the morphology of titanium alloy transformed after high temperature quenching, the hardness and strength of metallographic structure was increased when the grain fully refined and recrystallization[8]. From Table 4, it can be seen that the hardness of the machined material's surface has increased $13 \%$. The change range is not great, and the thickness of the heat-affecting layer is limited, thus will not have processing difficulty for the semi finish machining and fine machining following.

\section{Conclusion}

Through the test and analysis of electric machining, it can be concluded that the parameter of electrical machining have a great influence on the TC4 titanium alloy. When the discharge gap between two electrodes is increased or the supply voltage is increased, the current energy of the electric machining will larger, the processing reaction of the material will be more intense, and metal material removal is increased and processing efficiency will be improved, However, too fast processing speed will result in sintering of the workpiece surface, reducing the surface quality. When the workpiece rotating speed is increased, the surface quality of the workpiece will be improved, but the amount of material removal will be slightly reduced. Therefore, the smaller the discharge gap and the greater the voltage, the more obvious the effect of electrical processing on the TC4 titanium alloy, while the change of speed has little influence on the material properties.

Because of the low thermal conductivity and low compactness of the titanium alloy, the melting rate of metal is faster and its easily separated from the workpiece surface under the high temperature and high pressure, as a result, the electrical machining of titanium alloy has a high removal efficiency. In experiments, the removal of TC4 titanium alloy is up to $52.8 \mathrm{~mm}^{3} / \mathrm{s}$ by EDM, but the machined metal surface has obvious pits and drops, and the surface quality is rough.

From analyzing the change of processing surface layer tissue and hardness of processed TC4 titanium alloy, the surface microstructure of titanium alloy has a heat affected zone with thickness of $172.4 \mu \mathrm{m}$, and the metallographic structure of this region shows grain refinement and surface hardness is higher than matrix hardness about $13 \%$, but the change of hardness won't have much impact on the subsequent processing.

\section{References}

[1] J.C.Bai, F.Y.Feng and P.C.Liu: Technology of Non-traditional Machining (Harbin Institute of Technology Press, Harbin 2006), pp30-60, (In Chinese). 
[2] C.H. Liang, J.P. Zhou: The Short Arc Machining Technique and Its Application, Vol.12(2007) No.12, pp.92-94, (In Chinese).

[3] J.X. Ren, R.K. Kang, X.B. Wang: Grinding Technology for Difficult Machining Materials (Publishing House of Electronics Industry, Beijing 2011), pp56-58, (In Chinese).

[4] W.Y. Lv: Study on the Mechanism of Short Arc Machining Discharge (Neijiang Science \& Technology,Neijiang 2011), pp.110-130, (In Chinese).

[5] B. Ma: The Research and Analysis of Workpiece Surface Quality By Short Arc Machining (MS. Xin Jiang University, China 2011), pp.16-24, (In Chinese).

[6] H. He: The Research of Edm Milling Machine Tools and Key Technology Based on the Liquid Rotating Electrode (PHD, Harbin institute of technology, China 2011).

[7] C.F.Wang, L.Gu and Y.Jiang: Study on electrode compensation method for micro EDM (Electromachining \& Mould, Suzhou 2009),pp27-30, (In Chinese).

[8] Y.X. Hu, S.Y. Sun: Metallographic Experiment and Practical Technology (China Machine Press, Beijing 2012),pp136-138, (In Chinese). 